\title{
Grain-Size Prediction Model in Aluminum Castings Manufactured by Low-Pressure Technology
}

\author{
Ana Isabel Fernández-Calvo ${ }^{a *}$ Ibon Lizarralde ${ }^{a}$, Elisa Sal ${ }^{a}$, Patxi Rodríguez ${ }^{b}$, Edurne Ochoa de Zabalegui , \\ Igor $\mathrm{Cia}^{\mathrm{c}}$, Ariane Rios ${ }^{\mathrm{d}}$
}

${ }^{a}$ IK4-AZTERLAN, Aliendalde Auzunea 6, 48200-Durango, Spain

${ }^{\mathrm{b}}$ EDERTEK Technology Center of FAGOR EDERLAN Group, Isasi 6, 20500-Mondragón, Spain

${ }^{\mathrm{c}}$ MAPSA S. Coop., Ctra Echauri 11, 31160-Orcoien, Spain

${ }^{\mathrm{d}}$ EDERLAN S. Coop., Torrebaso 7, 20540-Eskoriatza, Spain

*e-mail: afernandez@azterlan.es

Received: 15 October 2018/Accepted: 22 December 2018/ Published online: 23 January 2019

This article is published with open access by AGH University of Science and Technology Press

\begin{abstract}
The grain refinement in a real casting manufactured by Low Pressure Die Casting (LPDC) such as wheels and steering knuckles depends on the grain-refinement potential of the metal and the geometry of the part/process parameters. For this study, the effect of the cooling rate on the AlSi7Mg alloy with different metal qualities in terms of grain refinement was tested. The grain size has been metallographically evaluated in cylindrical test pieces and in the real wheels and steering knuckles manufactured at the Mapsa and Fagor Ederlan foundries. The Thermolan $®$-Al system has been used to evaluate the nucleation potential in terms of grain size on a standard cup. The grain size has been modeled taking into account the effect of the cooling rate measured in the center of the cylindrical test parts and the different grain-size potential. Different grades of refinement have been tested. The grain size measured in a real casting (wheel and steering knuckle) was used to calibrate the model for a real part in LPDC for different grain-size potential.
\end{abstract}

Keywords:

grain refinement, AlSi7Mg alloy, thermal modulus, cooling rate, solidification evolution

\section{INTRODUCTION}

Aluminum-silicon alloys are the most widely used alloys for producing aluminum castings because they have very good foundry properties and may be adapted to span a large range of mechanical properties [1-3]. Grain-size refinement is one of the melt treatments commonly applied to these foundry alloys. The grain size has a very clear effect on the shrinkage behavior: well-refined alloys generally tend to display less shrinkage that is more finely dispersed. Thus, in those parts that comprise the zones that are difficult to adequately feed, a good grain refinement can decisively reduce the porosity [1-3].

The quality of the melt preparation in terms of grain refinement has been extensively studied by thermal analysis techniques for standard cups in the AlSi7Mg alloy [3-18]. However, obtaining a proper grain refinement in a standard cup does not assure that the grain refinement is correct in real parts (as was reported in a previous work for sand castings [12]).

The objective of the present work was to establish a quantitative relationship between the parameters from a thermal analysis with a standard cup using Thermolan®-Al $[11,12]$ and the local grain size in parts comprised of zones with different thicknesses and, consequently, different local solidification rates. In the first phase, an experimental metallic mold comprised of five cylinders of increasing diameters was used to establish this model. With such a simple geometry, the thermal moduli of the different cylinders could be easily defined and correlated to the local cooling rates (which ranged from $-31.5^{\circ}$ to $-5.1^{\circ} \mathrm{C} / \mathrm{s}$ depending on the modulus of the cylinder). Samples of the AlSi7Mg alloy with different potentials of grain refinement were prepared and cast to develop the desired model.

In the second phase, this model was validated on Low Pressure Die Casting (LPDC) wheels and steering knuckles manufactured at the Mapsa and Fagor Ederlan industrial facilities. They were cast after modifying the grain-refinement potential of the melt.

\section{DESIGN OF EXPERIMENTS}

The AlSi7Mg alloy with a Mg content of between 0.22 and 0.45 wt. $\%$ and a $\mathrm{Ti}$ content that varied between 0.08 and 0.17 wt.\% was studied under different grain-refinement conditions that were obtained by adding different quantities of Ti5B1 grain refinement (see chemical composition in Table 1). On Test References 9 and 10, both cylinders and wheels were cast. Previous to the casting of the test part, the grain-size potential was evaluated by the Thermolan $®$-Al system [11], with $G S_{\text {TH-Al }}$, ranging from 0.37 to $1.0 \mathrm{~mm}$. 
Table 1

Chemical analysis of investigated AlSi7Mg alloy [wt.\%] for cylinder castings and wheels

\begin{tabular}{|c|c|c|c|c|c|c|c|c|}
\hline & & $\mathrm{Si}$ & $\mathbf{F e}$ & $\mathrm{Cu}$ & Mn & Mg & $\mathrm{Ti}$ & $\mathrm{Sr}$ \\
\hline \multirow{8}{*}{ Cylinders } & 1 & 7.5 & 0.11 & $<0.02$ & $<0.05$ & 0.45 & 0.14 & 0.0257 \\
\hline & 2 & 7.1 & 0.11 & $<0.02$ & $<0.05$ & 0.39 & 0.14 & $<0.001$ \\
\hline & 3 & 7.1 & 0.11 & $<0.02$ & $<0.05$ & 0.40 & 0.17 & 0.0147 \\
\hline & 4 & 7.1 & 0.11 & $<0.02$ & $<0.05$ & 0.39 & 0.15 & 0.0163 \\
\hline & 5 & 7.1 & 0.11 & $<0.02$ & $<0.05$ & 0.40 & 0.16 & 0.0150 \\
\hline & 6 & 7.3 & 0.10 & $<0.02$ & $<0.05$ & 0.37 & 0.13 & 0.0183 \\
\hline & 7 & 7.3 & 0.09 & $<0.02$ & $<0.05$ & 0.31 & 0.14 & 0.0202 \\
\hline & 8 & 7.0 & 0.08 & $<0.02$ & $<0.05$ & 0.44 & 0.11 & 0.0192 \\
\hline \multirow{2}{*}{$\mathrm{C}+\mathrm{W}$} & 9 & 7.0 & 0.14 & $<0.02$ & $<0.05$ & 0.22 & 0.08 & 0.0240 \\
\hline & 10 & 7.1 & 0.15 & $<0.02$ & $<0.05$ & 0.27 & 0.13 & 0.0207 \\
\hline SK & 11 & 6.4 & 0.12 & $<0.02$ & $<0.05$ & 0.43 & 0.07 & 0.0165 \\
\hline
\end{tabular}

- C + W: cylinders and wheels

- SK: steering knuckle

Three different types of castings were tested to evaluate the grain size metallographically:

- a test piece with five cylinders (with heights equal to their diameters) was cast in a permanent metallic mold (see Figure 1);

- a real wheel and real steering knuckle were cast in industrial LPDC facilities following the usual die-cooling management strategies.

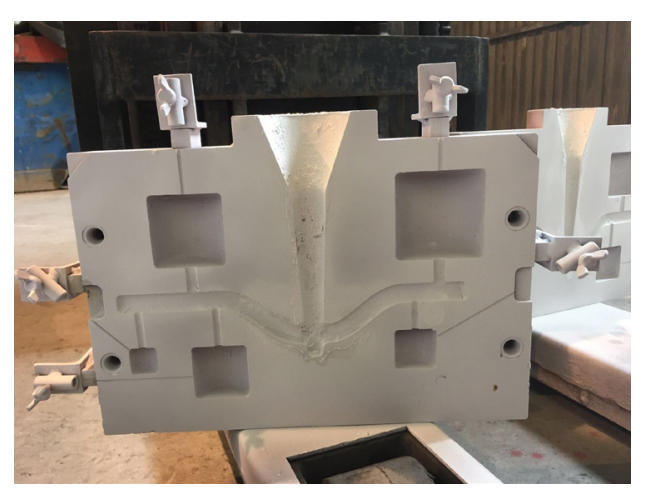

Fig. 1. Photo of one half of metallic mold designed for casting test cylinders with different thermal moduli

A thermocouple located at the center of each cylinder records the temperature evolution during the cooling and solidification. An example of the recorded curves of the cylinder mold is shown in Figure 2. As can be observed on the graph, the solidification time depends on the cylinder size; the larger the cylinder, the longer the time.

The die temperature of the cylinders was set at $350^{\circ} \mathrm{C}$ in order to achieve Secondary Dendrite Arm Spacing (SDAS) in the cylinders (similar to the observed values in selected industrial castings). The diameters, cooling rates at $635^{\circ} \mathrm{C}$, and SDAS values of the cylinders for a die temperature of $350^{\circ} \mathrm{C}$ are listed in Table 2 .

Figure 3 is a typical example of a cooling curve recorded with the AlSi7Mg alloy during its solidification in the standard Thermolan®-Al sand cup.

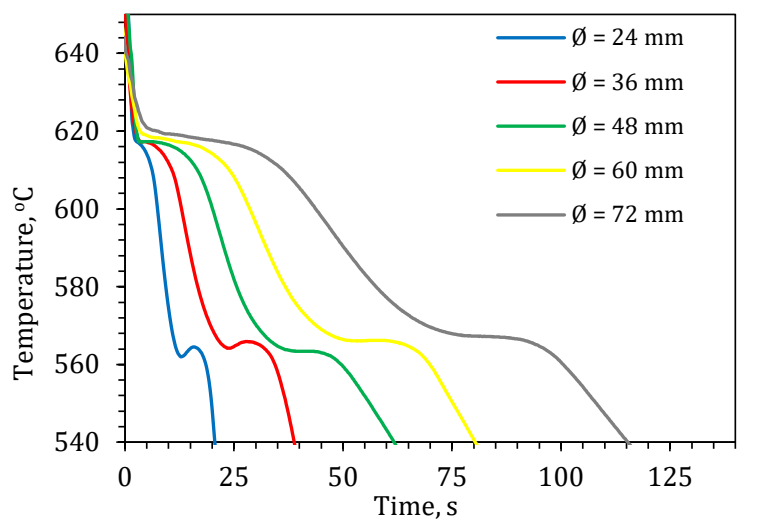

Fig. 2. Cooling curves of cylinders of Alloy 9

Table 2

Diameter (equal to height), SDAS, and cooling rate at $635^{\circ} \mathrm{C}$ of five test cylinders at die temperature of $350^{\circ} \mathrm{C}$

\begin{tabular}{cccccc}
\hline Cylinder diameter, $\mathbf{m m}$ & 24 & 36 & 48 & 60 & 72 \\
\hline Cooling rate, $^{\circ} \mathbf{C} / \mathbf{s}$ & -31.5 & -19.3 & -15.8 & -8.8 & -5.1 \\
\hline SDAS, $\boldsymbol{\mu m}$ & 22.9 & 28.3 & 30.5 & 35.1 & 42.6 \\
\hline
\end{tabular}

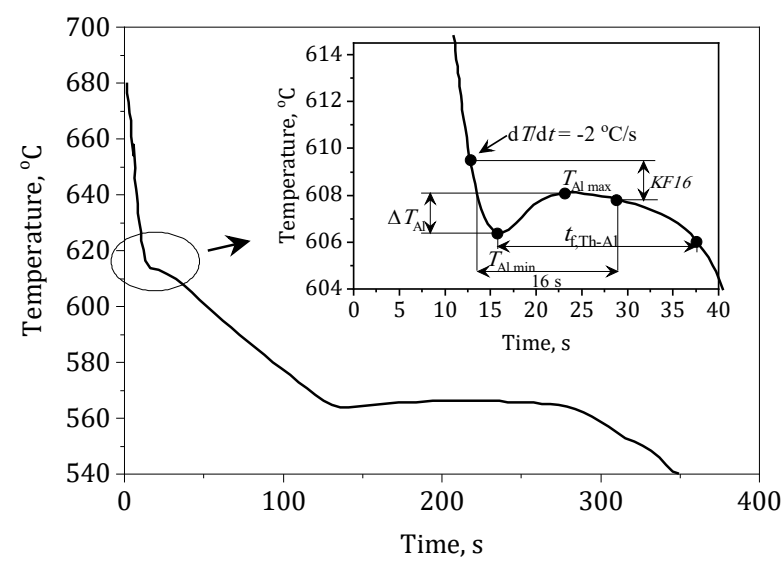

Fig. 3. Example of cooling curve in standard sand cup with definition of characteristic parameters for primary Al nucleation 
The insert shows an enlarged view of the part related to the start of solidification where the various parameters considered to be the characteristics of the nucleation of the (Al) primary phase are illustrated. These parameters are defined as $[9,11,12,18,19]$ :

- $\Delta T_{\mathrm{Al}}$ is the recalescence; i.e., the difference between the maximum $T_{\text {Almax }}$ and minimum $T_{\text {Almin }}$ temperatures;

- KF16 is defined as the difference between the temperature when the cooling rate is $2^{\circ} \mathrm{C} / \mathrm{s}$ and the temperature recorded 16 s later;

- $t_{\mathrm{f}, \mathrm{Th}-\mathrm{Al}}$ is the nucleation time; it is the time difference between the moment corresponding to the minimum in temperature and the time at which that temperature is again reached after recalescence. In the absence of recalescence, $t_{\text {fTh-Al }}$ is the time during which the temperature remains constant.

After the casting, all cylinders, wheels, steering knuckles, and thermal cups were cut and prepared for metallographic observation. For grain-size estimation, the samples were submitted to an electrolytic Baker's etching and observed under polarized light in an optical microscope. The grain size was estimated by the intercepted procedure.

In the polished samples without etching, the secondary dendrite arm spacing (SDAS) was measured by the mean linear intercepted method.

\section{RESULTS AND DISCUSSION}

\section{Thermal analysis cup results}

With each alloy, one standard thermal cup for analysis by Thermolan $®-A l$ and estimation of the above listed parameters was also cast. The thermal analysis parameters that are most significant for the prediction of grain size are the $t_{\mathrm{fTh}-\mathrm{Al}}, \mathrm{KF} 16$, and $\Delta T_{\mathrm{Al}}[11]$. All of these are considered in the equation of the grain-size prediction in the thermal cup. The values of the parameters for the standard cups and the corresponding predicted grain size $G S_{\text {Th-Al }}[11,12-14]$ for the cylinder castings, wheels, and steering knuckles are listed in Table 3.

Table 3

Thermal analysis parameters of standard sand cup and predicted $G S_{\text {Th-Al }}$ values by Thermolan $囚-A l$

\begin{tabular}{|c|c|c|c|c|c|}
\hline \multicolumn{2}{|c|}{ Ref. } & $\begin{array}{c}\boldsymbol{t}_{\mathrm{f}, \mathrm{Th}-\mathrm{Al}} \\
\mathbf{S}\end{array}$ & $\begin{array}{c}\text { KF16, } \\
{ }^{\circ} \mathrm{C}\end{array}$ & $\begin{array}{c}\Delta T_{A Y} \\
{ }^{\circ} \mathrm{C}\end{array}$ & 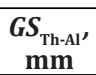 \\
\hline \multirow{11}{*}{ Alloy } & 1 & 1.4 & 5.80 & 0.0 & 0.43 \\
\hline & 2 & 8.8 & 3.62 & 0.7 & 0.97 \\
\hline & 3 & 0.8 & 6.43 & 0.0 & 0.37 \\
\hline & 4 & 9.8 & 3.33 & 0.7 & 0.95 \\
\hline & 5 & 4.0 & 5.05 & 0.0 & 0.54 \\
\hline & 6 & 8.2 & 4.04 & 0.6 & 0.96 \\
\hline & 7 & 1.0 & 5.90 & 0.0 & 0.40 \\
\hline & 8 & 4.0 & 4.55 & 0.0 & 0.52 \\
\hline & 9 & 9.0 & 4.20 & 0.6 & 1.00 \\
\hline & 10 & 3.2 & 5.10 & 0.0 & 0.51 \\
\hline & 11 & 1.6 & 5.30 & 0.0 & 0.44 \\
\hline
\end{tabular}

The effect of the grain refinement on the microstructure of the standard thermal cups is illustrated in Figure 4, where the grain size changes from 0.37 to $0.96 \mathrm{~mm}$ (the predicted $G S_{\text {Th-Al }}$ values) depending on the melt.

a)

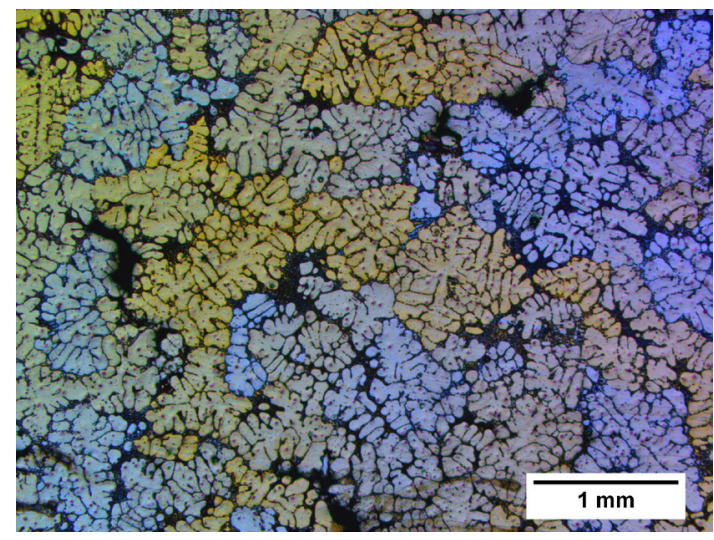

b)

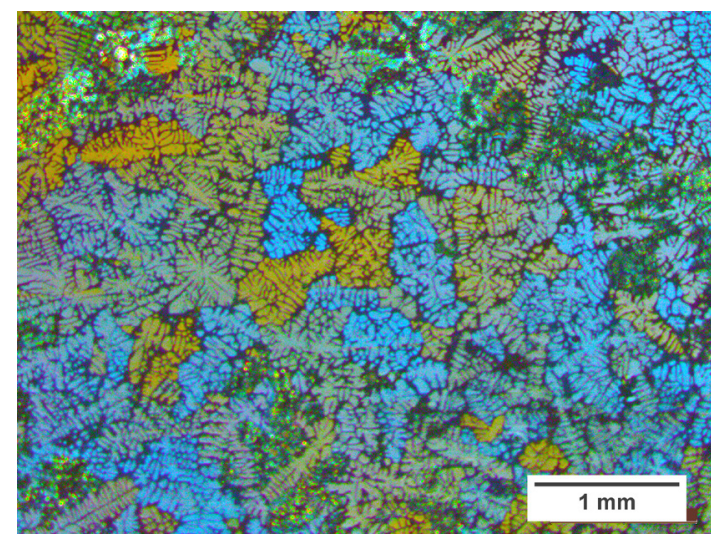

c)

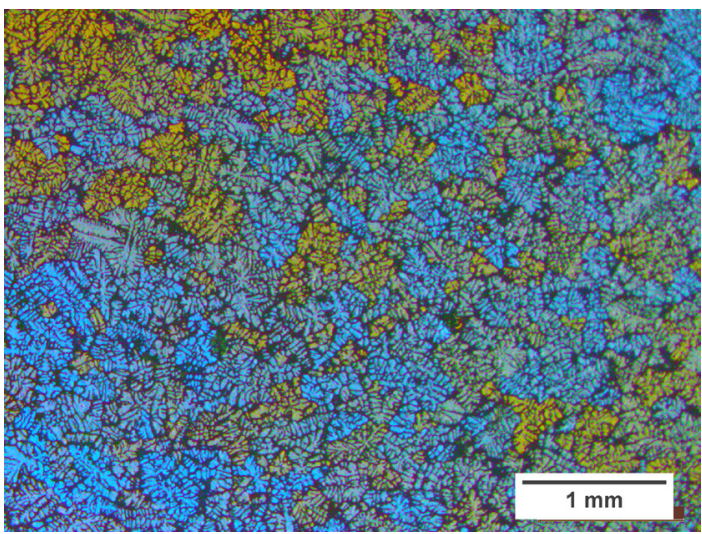

Fig. 4. Micrographs illustrating the range of grain size observed in thermal cups: a) $G S=0.96 \mathrm{~mm}$, b) $G S=0.52 \mathrm{~mm}$, c) $G S=0.37 \mathrm{~mm}$

Tables 1 and 3 may be checked to compare whether or not there is a simple relationship between the amount of the Ti-bearing master alloy in wt.\% and the grain refining. No grain refinement has been added in the coarser alloys $(2,4$, and 9$)$. It should be noted that the effectiveness of the grain refinement also depends on the Ti content of the alloy before the addition of the Ti-bearing master alloy, as the reaction of the latter may depend on its initial Ti content in the melt [17]. As a consequence, a chemical analysis of the metal is not sufficient to provide information regarding the grain-refinement efficiency. 


\section{Cylinder tests. Model development}

The effect of grain refinement as a consequence of the different cooling rates achieved in the cylinders is shown in Figure 5 for Alloy 9. The effect of the thermal modulus (i.e., cylinder diameter) on the cooling curve is illustrated in Figure 6 for the same melt and compared to the thermal analysis cup. Decreasing the casting modulus leads to higher cooling rates and lowers both the start of solidification and the (Al)-Si eutectic temperatures; this also leads to shorter overall and eutectic solidification times.

Considering the whole series of cooling curves, the cooling rate varied between $-31.5^{\circ}$ and $-5.1^{\circ} \mathrm{C} / \mathrm{s}$ at the start of solidification (see Table 2). The cooling rate of the thermal analysis cup is $-6.1^{\circ} \mathrm{C} / \mathrm{s}$; thus, it is much slower. This can be clearly seen in Figure 6.

a)

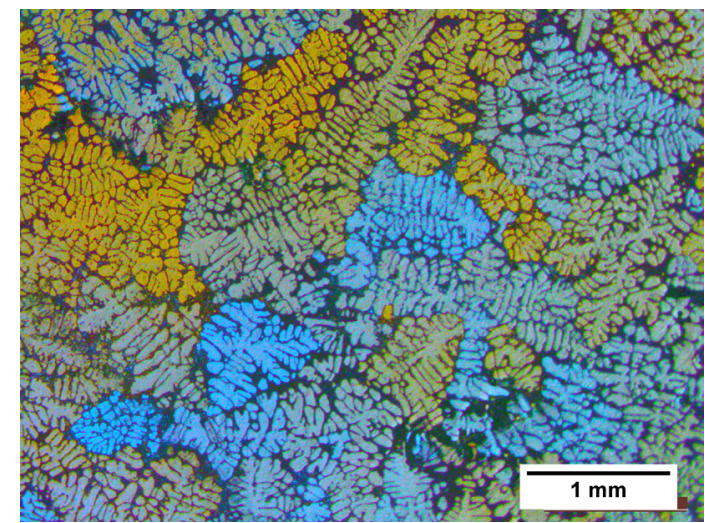

b)

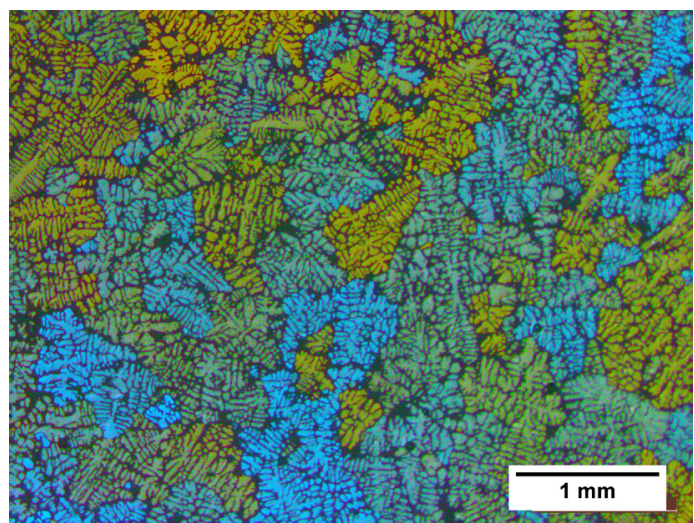

c)

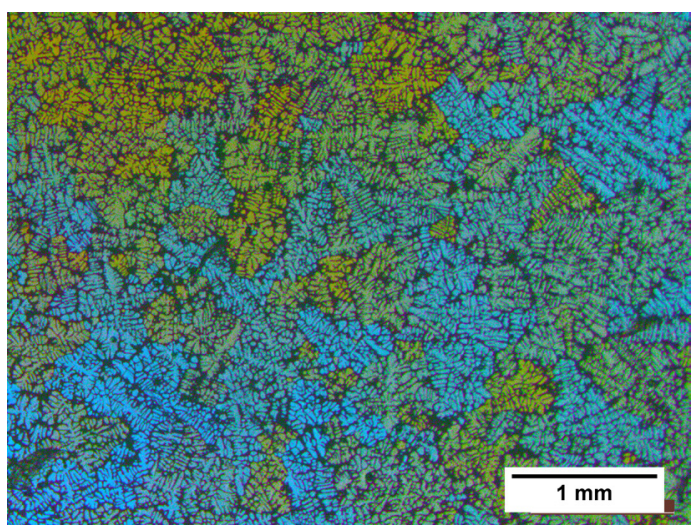

Fig. 5. Micrographs illustrating effect of thermal modulus on grain size for different cylinders for one melt $\left(G S_{\text {Th-Al }}=1.00 \mathrm{~mm}\right)$ : a) $G S=0.86 \mathrm{~mm}$, b) $G S=0.56 \mathrm{~mm}$, c) $G S=0.42 \mathrm{~mm}$

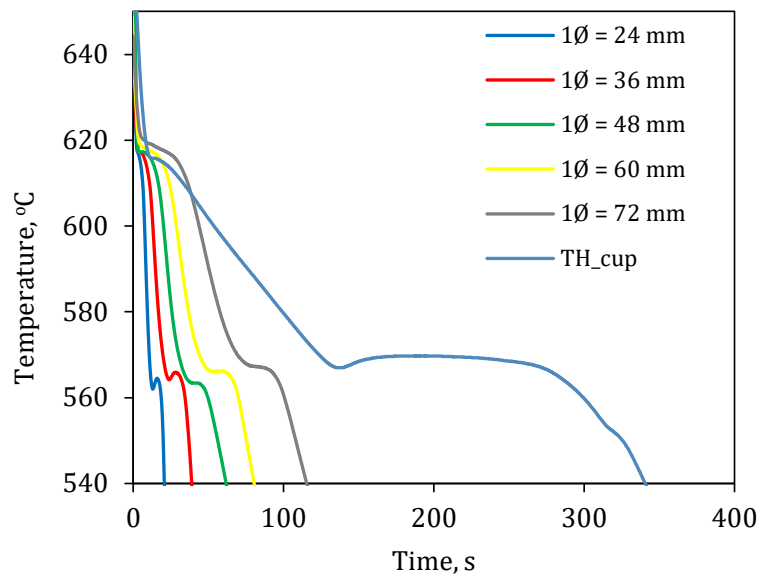

Fig. 6. Cooling curves of one melt obtained from cylinders with various moduli cast in permanent mold. Curves are labeled with corresponding diameters in $\mathrm{mm}$, and curve obtained on thermal analysis cup is added for comparison

Figure 7 shows the effect of the liquidus cooling rate on the grain size for the different cylinders cast with the ten melts. As expected, the grain size decreases when the cooling rate is higher.

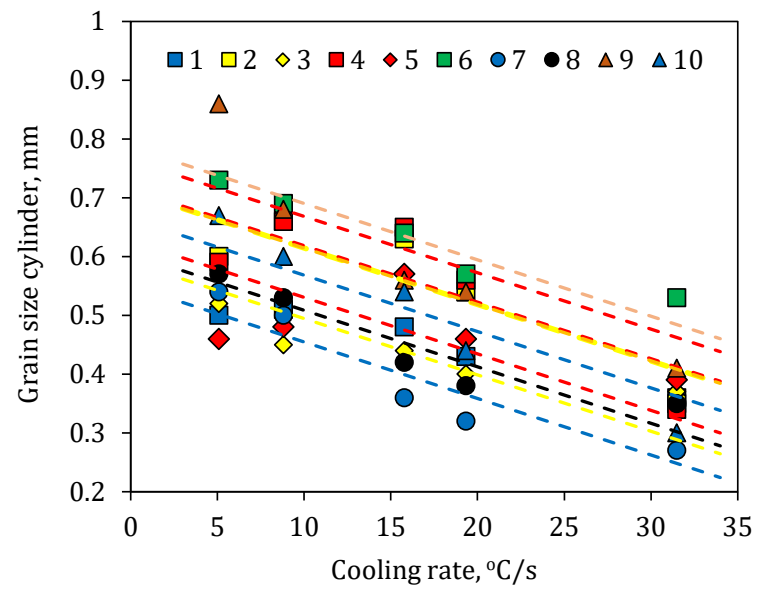

Fig. 7. Upper: grain-size evolution versus liquidus cooling rate for cylinder casting. Lower: grain-size evolution versus liquidus cooling rate for cylinder casting with calculated average slope (0.0096)

It is of some interest to note that a linear relationship may be established between the grain size and the liquidus cooling rate for the range investigated. It should be further stressed that the coefficients of this linear relationship are related to the grain refinement that is observed on the thermal analysis cup. A slight difference on the slope for the different trials and the grain-refinement conditions can also be observed. Due to the small difference, an average of the slopes has been taken, and the corresponding constant has been adjusted. On the cylinders cast in the sand molds, a correlation between the slope and the parameters of the grainsize prediction on the Thermolan $\AA-A l$ is obtained [12]. However, this correlation is not observed on the metallic mold samples; this is likely due to the high cooling rate and shorter solidification time. 
The constants of the curves have been plotted with the different parameters obtained from the thermal analysis; it was found that the appropriate parameter to use is solidification time $t_{\mathrm{f}, \mathrm{Th}-\mathrm{Al}}$ This is illustrated in Figure 8, where it can be seen that a line is again found.

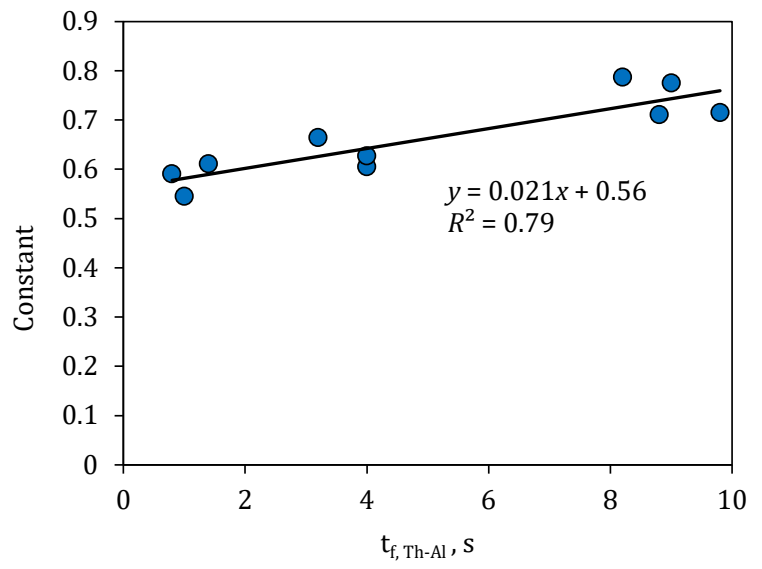

Fig. 8. Evolution of constant in regression lines versus solidification time $t_{\mathrm{f}, \mathrm{Th}-\mathrm{Al}}$ in thermal cup

Associating the fitting values for the constants give the following equations between the grain size in cylinder GS cylinder [mm], solidification time $t_{\mathrm{fTh}-\mathrm{Al}}$ from the thermal cup, and liquidus cooling rate $|\dot{\mathrm{C}}|$ of the cylinder described in Equation (1):

$$
G S_{\text {cylinder }}=0.0096|\dot{\mathrm{C}}|+\left[0.021 \cdot t_{\mathrm{f}, \mathrm{Th}-\mathrm{Al}}+0.56\right]
$$

The fitting parameter between the experimental data of the grain size of all of the cylinder castings and the predicted values, $R^{2}$ is high enough at 0.75 (see Figure 9).

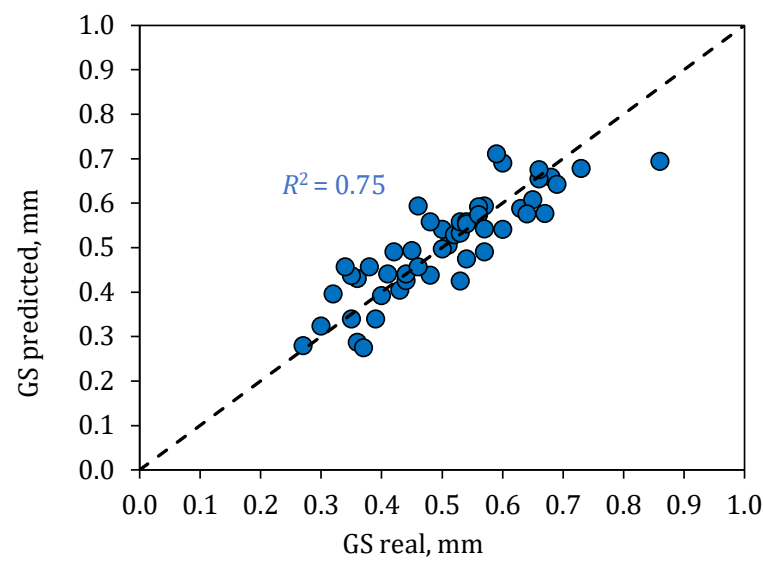

Fig. 9. Plot of experimental versus calculated values of grain size in cylinders using Equation (1). Dashed line is bisector

To validate the model in a complex real casting, two automotive components (a wheel and steering knuckle) have been selected and cast in Low Pressure Die Casting (LPDC) with different grain-size potentials. The local solidification time predicted by the simulation software in the selected wheel is shown in Figure 10. It is evident that the final thermal modulus and solidification time depend strongly on the geometry and the die's thermal management. Six different locations were selected to evaluate the grain size metallographically in the wheel and steering knuckle. An example of the grain-size variation in the wheel for the different solidification time areas in the case of a coarse grain size $\left(G S_{\text {Th-Al }}\right)$ of $1.0 \mathrm{~mm}$ evaluated by Thermolan $\AA$ - $\mathrm{Al}$ is shown in Figure 10. A variation between 0.45 and $0.65 \mathrm{~mm}$ is observed.

Solidification time [sec]

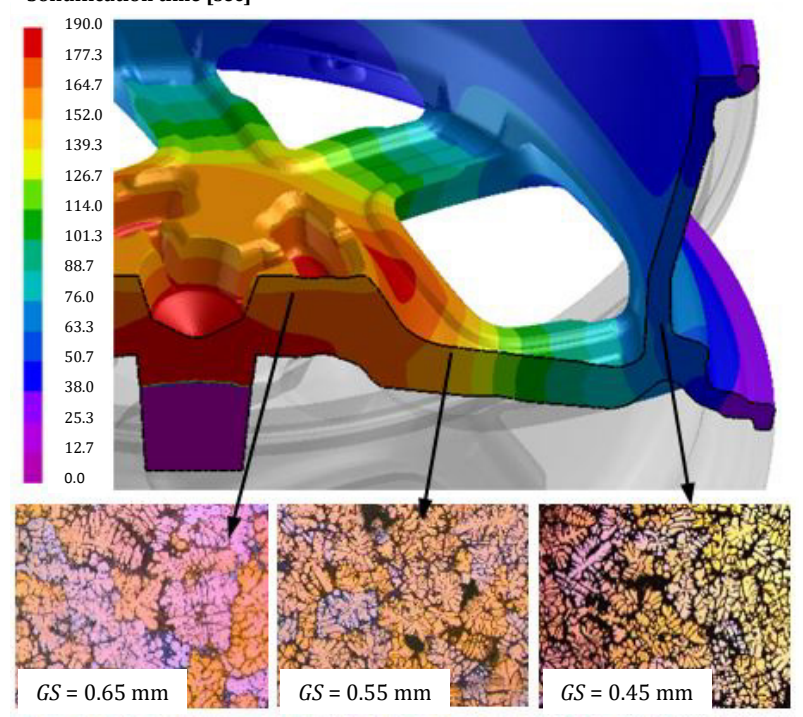

Fig. 10. Solidification time predicted by Procast, and grain size measured metallographically in real wheel with $G S_{\mathrm{Th}-\mathrm{Al}}=1.00 \mathrm{~mm}$

Among other factors, Equation (1) depends on the cooling rate; this is evaluated in the cylinders by analyzing the real cooling curve using thermocouples. For evaluating the cooling rate in the real parts, it is not easy to insert thermocouples in the mold; therefore, another way of calculating the cooling rate is needed. Thus, a correlation with an easier evaluating microstructural feature is desirable. For this purpose, SDAS was the selected parameter. The SDAS was evaluated in each cylinder of the ten series. The average value of the ten different melts was calculated and plotted versus the cooling rate (Fig. 11).

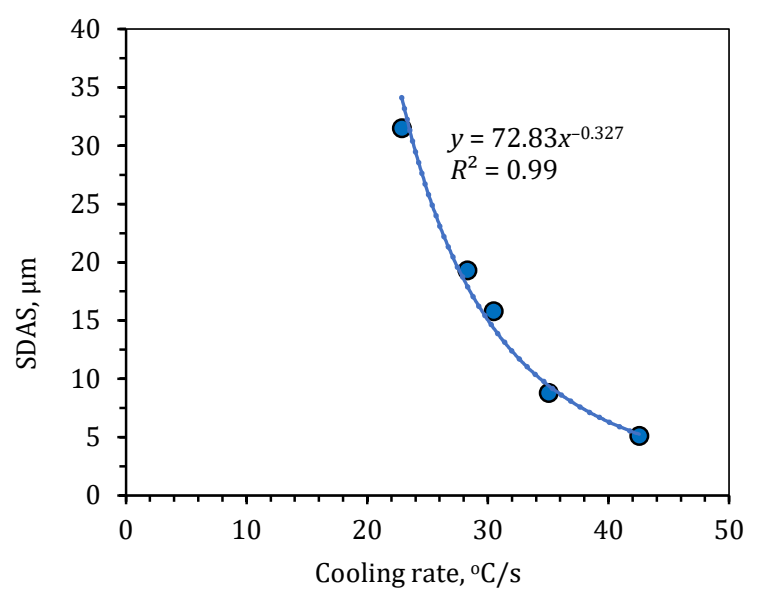

Fig. 11. Correlation between the SDAS and the cooling rate in each cylinder of the ten series 
In the literature, the SDAS data is often related to either the cooling rate or the time for a complete solidification $\left(t_{s}\right)$ according to Equation (2), where $\mathrm{A}$ and $\mathrm{n}$ are constants that depend on material properties [20-22].

$$
\mathrm{SDAS}=\mathrm{A} \cdot t_{\mathrm{s}}^{\mathrm{n}}
$$

An exponent of $1 / 3$ has been reported by several authors [20-22]; this is in agreement with the theoretical value expected for the model of a ripening controlled mechanism for the volume diffusion of the solute in the liquid [20].

$$
\mathrm{SDAS}=10 \cdot t_{\mathrm{s}}^{1 / 3}
$$

In order to correlate the SDAS with the cooling rate, the following equation is obtained by developing Equation (3):

$$
\mathrm{SDAS}=K \cdot|\dot{\mathrm{C}}|^{-1 / 3}
$$

Thus, a good correlated equation is obtained to relate the cooling rate with the SDAS:

$$
\operatorname{SDAS}_{\text {cylinder }}=72.83|\dot{\mathrm{C}}|^{-0.327}
$$

\section{Real parts. Model validation}

In order to validate the developed model for the grain-size prediction described in Equation (1), a wheel and steering knuckle cast in a low-pressure die casting are selected (see Figure 12).
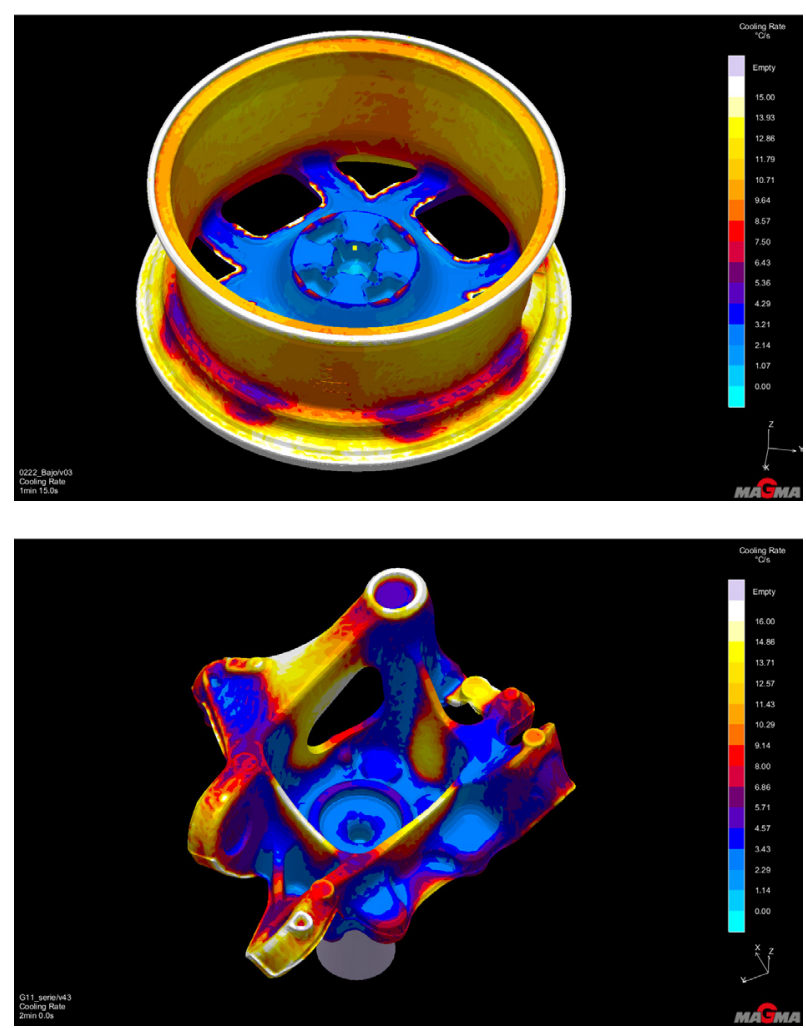

Fig. 12. The wheel and the steering knuckle selected for the model validation
The grain-size data evaluated in the two wheels cast with different nucleation potential melts evaluated by Thermolan ${ }^{\circledR}$ - $\mathrm{Al}$ is listed in Table 3 . The grain size in the real casting depends significantly on the grain-size potential evaluated in Thermolan-Al as well as the cooling rate. Significant differences can be observed in the SDAS evaluation between the different zones of the casting for each melt (from 28 to $43 \mu \mathrm{m}$ ), so a difference is also observed in the cooling rate evolution on the part.

Considering the SDAS obtained metallographically and that relating to the theorical cooling rate calculated by Equation (5), the following correlation is obtained between the cylinders and the real parts (see Figure 13).

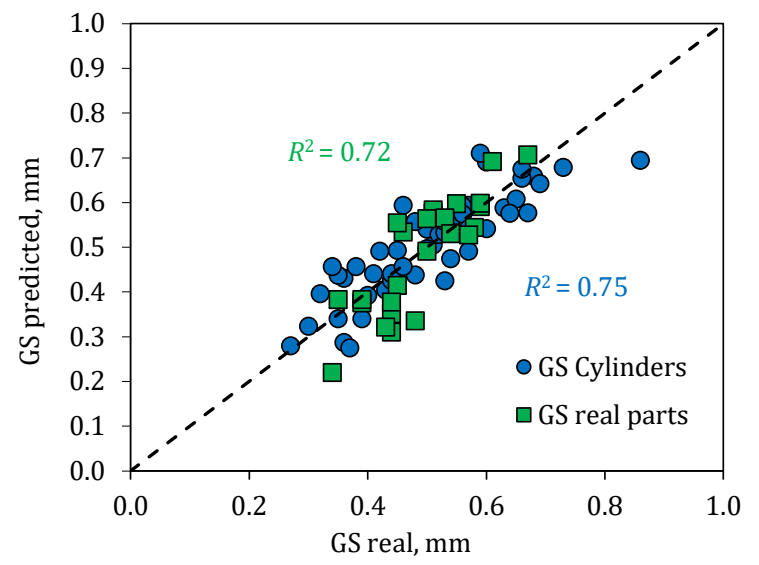

Fig. 13. Plot of experimental versus calculated values of grain size in cylinder casting, wheels, and steering knuckles

\section{CONCLUSIONS}

The grain refinement in a real casting manufactured by low pressure die casting (LPDC) depends on the grain refinement potential of the metal, the casting geometry, and the die's thermal management.

For this study, the effect of the cooling rate on the AISi7Mg alloy with different metal qualities in terms of grain refinement was tested. The grain size has been metallographically evaluated in cylindrical test pieces as well as in real wheels manufactured at MAPSA. The Thermolan ${ }^{\circledR}-\mathrm{Al}$ system was used to evaluate the nucleation potential in term of grain size on the standard thermal analysis cup.

Thus, a thermal analysis of the melt prior to casting allows us to predict whether the desired grain size will be obtained in different locations of the part or if corrective actions must be taken to improve the grain-refinement potential of the melt.

The most important conclusions are as follows:

- for each melt, a linear relationship was observed between the grain size and the cooling rate of the cylinder castings;

- an exponential equation is obtained between the SDAS values and the cooling rate of the cylinders;

- it is possible to formulate an equation that provides grain size as a function of the cooling rate and nucleation time evaluated from the cooling curve recorded on the standard thermal cup; namely, $t_{\mathrm{f}, \mathrm{Th}-\mathrm{Al}}$; 
- the model for grain-size prediction developed by the cylinder castings is validated in several wheels and steering knuckles;

- knowing the cooling rate, it is possible to predict from the standard thermal analysis whether the grain refining treatment will be appropriate for the part being cast or if it must be adjusted.

\section{Acknowledgements}

This research was financially supported by the Spanish Ministerio de Economía y Competitividad, RETOS program, No. RTC-2015-3822-4.

\section{REFERENCES}

[1] ASM International (1992). ASM Metals HandBook. Volume 15: Castings. 9th Ed., Materials Park, Ohio, USA

[2] Gilbert Kaufman J. \& Rooy E.L. (2005). Aluminum alloy castings: properties, processes and applications. AFS, ASM International, Materials Park, Ohio, USA.

[3] Gruzleski J.E. \& Closset B.M. (1990). The treatment of liquid aluminum-silicon alloys. The American Foundrymen's Society Inc., Des Plaines, Illinois, USA.

[4] Menk W., Speidel M. \& Döpp R. (1992). Die thermische Analyse in der Praxis der Alumiumgiesserei. Giesserei, Zurich: ETH Zürich.

[5] MacKay R.I., Djurdjevic J.H., Sokolowski J.H. \& Evans W.J. (2000). Determination of eutectic Si particle modification via a new thermal analysis interpretive method in 319 alloy. AFS Transaction, 108, 511-520.

[6] Jiang J., Sokolowski J.H., Djurdjevic M.B. \& Evans W.J. (2000). Recent advances in automated evaluation and on-line prediction of Al-Si eutectic modification level. AFS Transaction, 23, 505-510.

[7] Heusler L., Schneider W., Stolz M., Brieger G. \& Hartmann D. (1997). Neuere Untersuchungen zum Einfluss von Phosphor auf die Veredelung von Al-Si-Gusslegierungen mit Natrium oder Strontium. Giesserei-Praxis, 82, 66-76.

[8] Apelian D., Sigworth G.K. \& Whaler K.R. (1984). Assessment of grain refinement and modification of Al-Si foundry alloys by thermal analysis. AFS Transaction, 92, 297-307.

[9] Günther B. \& Jürgens H. (1984). Automatisierte Durchführung der thermischen Analyse zur Ermittlung des Keimzustandes von Al-Schmelzen und der erzielten Korndroße an Bauteilen aus Aluminium-Guss. Giesserei, 71(24), 928-931.
[10] Niklas A., Abaunza U., Fernández-Calvo A.I., Lacaze J. \& Suárez R. (2011). Thermal analysis as a microstructure prediction tool for A356 aluminium parts solidified under various cooling conditions. China Foundry, 8(1), 89-95.

[11] Lacaze J., Ferdian D., Lizarralde I., Niklas A., Eguskiza S. \& Fernández-Calvo A.I. (2014). Improved grain size prediction in aluminium-silicon alloys by thermal analysis. 71st World Foundry Congress (WFC 2014): Advanced Sustainable Foundry, 19-21 May 2014, Bilbao, Spain. Curran Associates, Inc., 1216-1222.

[12] Fernández-Calvo A.I., Lizarralde I., Eguskiza S., Santos F. \& Niklas A. (2014). Improved precision in grain size Prediction by thermal analysis and statistical analysis in aluminium castings. 71st World Foundry Congress (WFC 2014): Advanced Sustainable Foundry, 19-21 May 2014, Bilbao, Spain. Curran Associates, Inc., 1319-1328.

[13] Lizarralde I., Niklas A., Fernández-Calvo A.I. \& Lacaze J. (2013). Effect of the thermal modulus and mould type on the grain size of AlSi7Mg alloy. In: Sadler B.A. (ed.), Light Metals 2013. The Minerals, Metals \& Materials Series. Springer, Cham, 327-331.

[14] Barrenengoa J. (2011). Proyecto fin de carrera, sistema predictivo de la calidad metalúrgica para las aleaciones de fundición de aluminio AlSi7Mg. Escuela Universitaria de Ingeniería Técnica de Minas y Obras Públicas, UPV.

[15] Bekaert F. \& Wettinck E. (1996). Study of the grain refinement of A 356 and its control by thermal analysis. Aluminium, 72, 442-447.

[16] Sigworth G.K. \& Kuhn T.A. (2007). Grain refinement of aluminum casting alloys. International Journal of Metalcasting, 1(1), 31-40.

[17] Spittle J.A. (2008). Grain refinement in shape casting of aluminium alloys - Part I. Foundry Trade Journal, 181(3659), 308-314.

[18] Argyropoulos S., Closset B., Gruzleski J.E. \& Oger H. (1983). The quantitative control of modification of Al-Si foundry alloys using a thermal analysis technique. AFS Transaction, 91, 350-357.

[19] Ibarra D.C. (1999). Control of grain refinement of Al-Si-alloys by thermal analysis. PhD thesis, McGill University of Montreal, Canada.

[20] Bouchard D. \& Kirkaldy J.S. (1997). Prediction of dendrite arm spacing in unsteady and steady state he flow. Metallurgical and Materials Transactions B, 28, 651-663.

[21] Carpentier D. (1994). Modélisation de la formation des microporosités lors de la solidification d'alliages a base d'aluminium. PhD thesis, Institut National Polytechnique de Lorraine, Nancy, France.

[22] Okamoto T. \& Kishitake K. (1975). Dendritic structure in uniderectionally solidified aluminum, tin and zinc base binary alloys. Journal of Crystal Growth, 29, 137-146. 